\title{
On-Board Ultrasonic Water-in-Diesel Emulsion (WiDE) Fuel System for Low-Emission Diesel Engine Combustion
}

\author{
KOTARO KOJIMA ${ }^{1}$ and JUN KOJIMA, Broadway Creek Homeschool Academy, Medina, OH, USA.
}

ABSTRACT. Water-in-diesel emulsion (WiDE) fuel is a promising alternative fuel capable of reducing nitrogen oxides $\left(\mathrm{NO}_{X}\right)$ and particulate matter $(\mathrm{PM})$ in diesel engine exhaust while simultaneously preserving combustion efficiency of the engine. However, the instability of WiDE fuel - and the high costs of production and transportation - hinder its commercialization and widespread use. An on-board ultrasonic WiDE fuel supply system is proposed as a solution to this challenge. This system allows diesel fuel and water to be continuously emulsified on-board a diesel vehicle. Diesel fuel and water, stored in individual reservoirs, are conveyed in specific ratios to an in-line mixing chamber and are rapidly homogenized by ultrasonic cavitation before entering the fuel injectors. The produced emulsion fuel is then supplied to the engine. A proof-of-concept study was conducted to compare exhaust emissions between emulsion fuels and conventional fuels. Open-flame combustion experiments were conducted using a lab-scale burner to test the system with both diesel and biodiesel fuels. Unique optical diagnostics and image-processing techniques were used to estimate PM emission levels. Results showed a reduction of PM with the use of the onboard WiDE system compared to traditional diesel fuels. PM emissions from biodiesel fuel were reduced by $58 \%$ when water-in-biodiesel emulsion was combusted with $2 \%$ water. Additionally, a PM emission reduction of $35 \%$ was achieved through emulsification of diesel fuel with $2 \%$ water. This prototype demonstrates the potential for the on-board WiDE fuel supply concept to both overcome the traditional barriers hindering the commercialization of WiDE fuel and preserve its low-emission and superior combustion efficiency characteristics.

\section{INTRODUCTION}

The diesel engine is one of the most efficient and reliable energy conversion devices commonly available today (Lloyd and Cackette 2001). Due to their high torque, exceptional fuel economy, durability, low maintenance, and heavy-duty application, diesel engines are the major propulsion power sources in the day-to-day life of modern society. Diesel engines power much of the world's land and marine transportation, generate electrical power, and are widely used for a variety of agricultural, construction, industrial, and military applications (Kean et al. 2000). Despite its many advantages, however, the diesel engine is one of the largest contributors to global environmental pollution, and will remain so, with substantial growth expected in worldwide diesel vehicle use (Prasad and Bella 2010).

Hazardous pollutants emitted from diesel enginesparticularly nitrogen oxides $\left(\mathrm{NO}_{X}\right)$ and particulate matter (PM) - not only damage our environment, but also threaten human health (Lin and Wang 2003). Organizations such as the National Institute

${ }^{1}$ Address correspondence to Mr. Kotaro Kojima, Broadway Creek Homeschool Academy, 4630 Foote Rd., Medina, OH 44256. Email: kotaro.d.kojima@gmail.com for Occupational Safety and Health (NIOSH), the International Agency for Research on Cancer (IARC), the World Health Organization (WHO), and the US EPA have reviewed epidemiological and experimental studies related to diesel engine exhaust and lung cancer, and have classified diesel engine exhaust gas mixture as potential carcinogens for humans (Kagawa 2002). Exposure to $\mathrm{NO}_{X}$ and PM emissions in diesel engine exhaust has been shown to contribute to an array of cardiovascular and respiratory illnesses, including lung cancer, asthma, chronic bronchitis, and ischemicheart disease (Sydbom et al. 2001; Neuberger et al. 2004; Pope III and Dockery 2006; Lewtas 2007; Reşitoğlu et al. 2015).

Growing public concern for environmental problems and adverse health issues_caused by diesel engine exhaust emissions - has resulted in increasingly stringent regulations worldwide. These enforced environmental policies continue to drive a major research endeavor: minimize emissions from diesel engines already in operation as well as those 
manufactured in the future. Various emission control strategies have been proposed from fuel reformulations to engine retrofits; however, most of the emission reduction efforts have been focused on retrofitting existing diesel engines with hardware-based pollutantcontrol equipment.

Diesel oxidation catalysts (DOCs) and diesel particulate filters (DPFs) have been used extensively for the reduction of PM emissions in diesel engine exhaust. DOCs are inexpensive and robust, are employed for off-road applications, and can achieve PM reductions of $25 \%$ to $60 \%$ (Stein 1996; Kerminen et al. 1997; Bagley et al. 1998; Alander et al. 2004). DPFs are able to reduce PM emissions up to $90 \%$ and work effectively on engines that can maintain typical working exhaust temperatures (Van Setten et al. 2001). Unfortunately, these retrofit systems lead to high combustion temperature, resulting in high $\mathrm{NO}_{X}$ emissions. Hence, researchers around the globe are researching various options to reduce peak combustion temperature, to cut $\mathrm{NO}_{X}$ emissions, without declining engine performance.

Other exhaust after-treatment devices-such as selective catalytic reduction (SCR) and $\mathrm{NO}_{X}$ absorber catalysts (NAC) - are designed to be able to reduce the formation of $\mathrm{NO}_{X}$ considerably (Koebel et al. 1996; Gill et al. 2004; Guan et al. 2014). Nevertheless, the techniques that are used to decrease $\mathrm{NO}_{X}$ lead to an increase in PM and black smoke (Basha and Anand 2011). In addition, these devices tend to increase the fuel consumption of the engine (Nadeem et al. 2006).

Most hardware-based exhaust control technologies and advanced fuel injection systems are not capable of simultaneously reducing $\mathrm{NO}_{X}$ and $\mathrm{PM}$ emissions while maintaining engine performance. It is difficult to simultaneously lower both $\mathrm{NO}_{X}$ and engine-out emissions of PM due to the trade-off relationship between $\mathrm{NO}_{X}$ and PM: changes that decrease $\mathrm{NO}_{X}$ pollutants often increase the engine-out emissions of PM, and vice versa. For example, lowering the maximum temperature reached during combustion reduces $\mathrm{NO}_{X}$ emissions but inhibits the complete oxidation of soot, thereby increasing PM emissions. This notorious $\mathrm{NO}_{X}$-PM tradeoff presents a critical challenge to diesel emission reduction strategies.

Therefore, a need exists for a disruptive, costeffective, technology that concurrently reduces $\mathrm{NO}_{X}$, PM, and black smoke emissions in the exhaust, all without penalizing the combustion efficiency of the engine. This technology must also be applicable to both existing and new diesel engines. One such possibility is to develop fuel-based solutionswhich do not rely on new hardware-to control the combustion process and hence the emissions.

In recent decades, water-in-diesel emulsion (WiDE) fuel has emerged as a promising alternative fuel with the capability of simultaneously reducing the formation of $\mathrm{NO}_{X}$ and $\mathrm{PM}$, while enhancing combustion efficiency (Lif and Holmberg 2006; Ithnin et al. 2014). An emulsion is a mixture of 2 immiscible liquids formed by mechanical blending. In an emulsion, one of the liquids (the dispersed, or internal, phase) is uniformly distributed as small droplets throughout the other liquid (the continuous, or external, phase). For example, water $\left(\mathrm{H}_{2} \mathrm{O}\right)$ and conventional diesel fuel oil are inherently immiscible. However, through vigorous mechanical agitation or homogenization, these 2 liquids can be emulsified into a homogeneous mixture wherein micro-droplets of water (the dispersed phase) are universally dispersed throughout the diesel fuel (the continuous phase). The resulting emulsion of diesel fuel and water is commonly known as a water-in-diesel emulsion (WiDE) fuel.

The reduction in $\mathrm{NO}_{X}$ emissions has been attributed to the decrease in the peak flame temperature in the cylinder; a result of the latent heat required for the vaporization of the liquid water in the emulsion fuel (Farfaletti et al. 2005). The phase transition of the liquid water to steam (which occurs in the combustion chamber) absorbs the heat during the combustion, leading to a lower in-cylinder temperature. This cooling effect, obtained by the presence of water in the combustion chamber, significantly reduces NO production and is particularly efficient in suppressing the formation of $\mathrm{NO}_{X}$ (Alahmer et al. 2010; Maiboom and Tauzia 2011).

The reduction of PM when using WiDE fuel is primarily attributed to the improved air-fuel mixing and enhanced atomization caused by a distinct phenomenon called micro-explosion (Kadota and Yamasaki 2002). When the WiDE fuel is ignited, and reaches the boiling point of water, the water droplets (encapsulated by the diesel fuel droplets) evaporate. This water-droplet vaporization causes the explosion of the continuous hydrocarbon phase, shattering the 
diesel fuel droplets into particles typically measuring less than $20 \mu \mathrm{m}$ in diameter. This enhances the air/ fuel mixing process and leads to improved combustion efficiency. The net result is the reduction of both soot formation and unburned hydrocarbons, or PM emissions (Armas et al. 2005; Ghojel et al. 2006; Ochoterena et al. 2010). The addition of water in the emulsion also augments the formation of hydroxyl radicals, which leads to the oxidation of soot and improved burnout of soot particles (Ithnin et al.2015).

In spite of its advantages, a major concern of waterin-diesel emulsion fuel is its inherent thermodynamic instability; the constituent parts have a tendency to separate after exceeding a stability period (Binks 1998). IfWiDE fuel is not agitated periodically, water droplets dispersed in the fuel have a tendency to coalesce and, over time, the system breaks up into bulk diesel fuel oil and water phases. Because of emulsion destabilization, WiDE fuel cannot be stored for extended periods of time in fuel tanks at gasoline stations like traditional fuels. The destabilized fuel, due to the large coalesced droplets of water, would induce engine failure or knocking. The exposed water contact would also severely damage hardware components in the engine, such as fuel injector electronics. Additionally, the manufacturing of WiDE fuel (requiring dedicated factories with special equipment) and its transportation to desired locations would incur large expenses. Hence, there is a need for a technology capable of eliminating the barriers (i.e., emulsion instability and infrastructure/ transportation expenses) to the commercialization of WiDE fuel-while maintaining its low-emission levels and superior combustion efficiency.

To address the above issues, this research aims to (1) develop a novel on-board ultrasonic waterin-diesel emulsion (WiDE) fuel supply system for implementation in diesel engines and (2) conduct a proof-of-concept study. Utilizing ultrasonic cavitation, this unique in-line system was designed to continuously mix specific fuel-to-water ratios on-board an operating diesel vehicle, and steadily feed this freshly-produced WiDE fuel to the fuel injectors in real time. A proofof-concept prototype of the system was constructed and tested (using conventional diesel fuel and vegetable-oilbased biodiesel) for emission reduction. Open-flame combustion experimentation was conducted, and various optical analysis procedures — including flamecolor PM emission measurements and laser-based fuel spray visualizations_-were performed.

\section{METHODS AND MATERIALS On-Board Ultrasonic WiDE Fuel Supply System Overview}

An on-board ultrasonic water-in-diesel emulsion (WiDE) fuel supply system has been designed for diesel engine implementation. Fig. 1 shows the overall configuration of the technology in a standard diesel engine system. The in-line WiDE fuel system is integrated close to the common rail/ fuel injection system of the diesel engine. Key to this design is a emulsification (mixing) chamber containing a high-intensity ultrasonic processor (transducer) and a solenoid pulse control valve to continuously make WiDE fuel using high-pressure ultrasonic cavitation; this operates in real time and on-board the diesel vehicle. The produced WiDE fuel is then supplied directly to the diesel engine for combustion ignition.

As shown in Fig. 1, a single water reservoir supplies water for the WiDE fuel and the windshield washer fluid. During engine operation, diesel fuel and water are pumped out of their respective reservoirs and converge at the three-way solenoid pulse control valve, which regulates the fuel-towater ratio. Diesel fuel and water are quantitatively conveyed, in specific fuel-to-water ratios (e.g., 7:1, $6: 1,5: 1$ ), into the in-line emulsification (mixing) chamber. The 2 immiscible liquids (i.e., diesel fuel and water) are rapidly homogenized ( $<2$ seconds) by ultrasonic cavitation generated by the ultrasonic liquid processor (transducer) in the mixing chamber. The newly made WiDE fuel is then fed into the common rail where it is injected into the combustion chamber for compression ignition. Unused fuel is looped back to the emulsification chamber where it is re-emulsified with constituent fuel and water.

Once integrated into diesel engines, the true economical benefit of the WiDE fuel can be realized. WiDE fuel can be formed near the fuel injectors, during engine operation, and consumed immediately for combustion. This approach removes the concerns of emulsion instability in the fuel tank or fuel dispensers. It also eliminates the needs for mass production processes at chemical plants and subsequent transportation to fueling sites. 


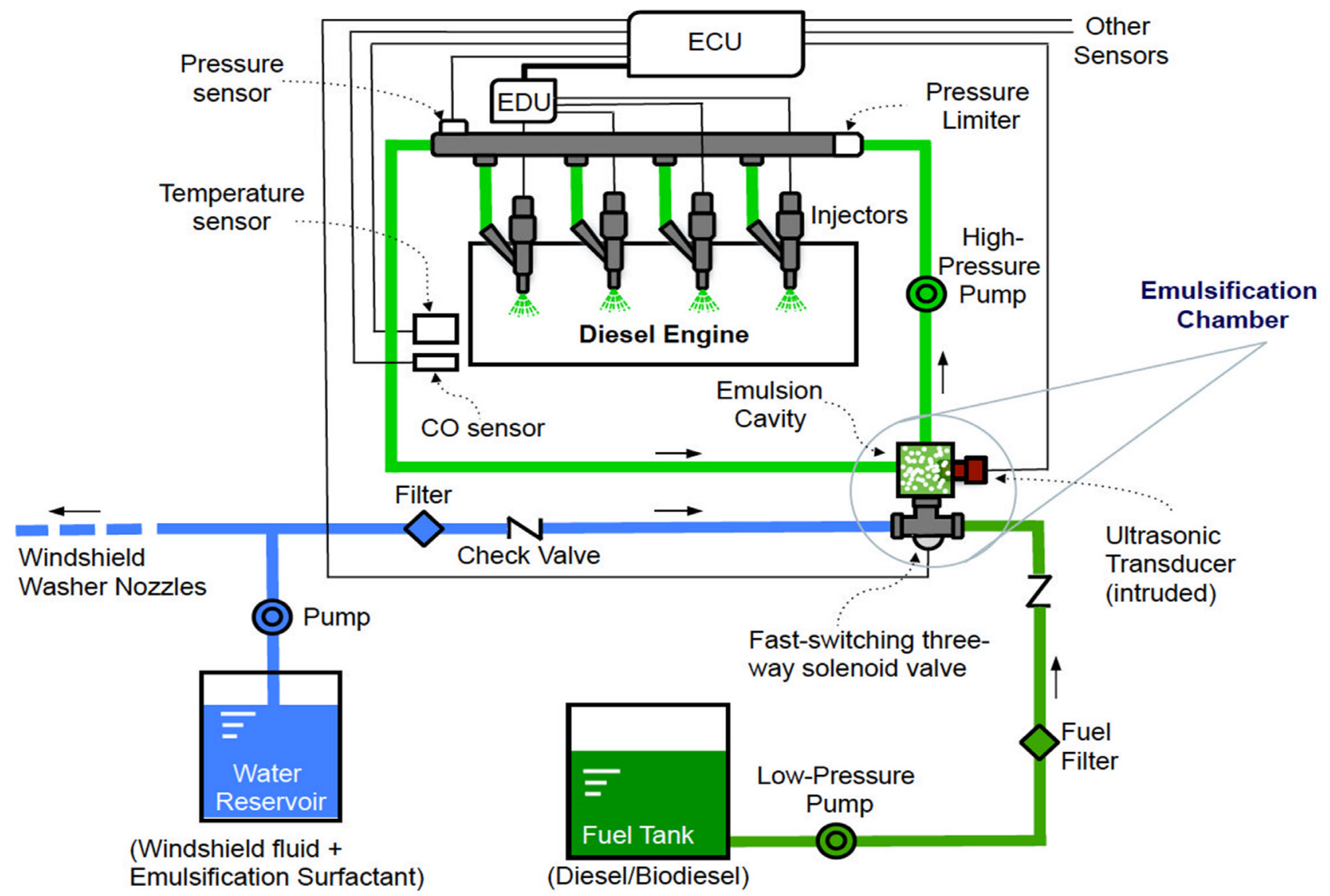

FIGURE 1. Schematic of on-board ultrasonic water-in-diesel emulsion (WiDE) fuel supply system integrated into a diesel engine common rail/fuel injection system. ECU stands for electronic control unit. EDU stands for electronic driver unit. The water reservoir dually supplies water to the WiDE fuel supply system and the windshield washer nozzles.

\section{Dual-Purpose Water Mixture}

The water for emulsion was a combination of (1) distilled water, (2) methyl alcohol to prevent freezing $\left(\mathrm{CH}_{3} \mathrm{OH}\right.$; Duda Energy $\left.{ }^{\circledR}\right)$, and (3) a surfactant for corrosion prevention (Clear EX, Lion Specialty Chemicals). The surfactant contained polyoxyethylene (as a nonionic surfactant), amine compounds (for corrosion prevention), and a chelating agent (for antibacterial purposes). This water for emulsion can also function as windshield washer fluid (because of its anti-freezing, hydrophobic properties) and thus serve as a dual-purpose water mixture, eliminating the need for an additional water reservoir and water pump in the diesel engine.

\section{Anti-Freezing and Corrosion Prevention of the Dual-Purpose Water Mixture}

A chemical experiment was conducted to test the anti-freezing and rustproof performance of the dualpurpose water mixture. Samples of the water mixture were prepared, varying the methylalcohol content in the water from $5 \%$ to $30 \%$ in $5 \%$ increments. The samples were set in an environment with an average temperature of $-25^{\circ} \mathrm{C}$ for 10 hours. Crystallization was observed in methyl alcohol concentrations below $30 \%$. However, the mixture with $30 \%$ methyl alcohol remained liquid, without any sign of crystallization. This is in agreement with the fact that a typical commercial windshield washer fluid has a 30\% to $40 \%$ methyl alcohol concentration.

To test anti-corrosion ability, samples of the water mixture were prepared in 5 different containers, varying surfactant content from $1 \%$ to $10 \%$ in $2 \%$ increments. A 5-gram piece of steel was submerged in each water mixture for 10 days, after which the metal was observed for the degree of corrosion. For water mixtures with surfactant concentrations below 7\%, the submerged steel pieces showed signs of corrosion and the water mixture was slightly discolored. The steel in the water mixtures with $7 \%$ and $10 \%$ surfactant concentrations did not show any surface corrosion after 10 days. 
These results suggest that a minimum of $30 \%$ methyl alcohol concentration and 7\% surfactant concentration is required for the water mixture to be a rustproof and anti-freezing solution. If this dualpurpose water were mixed with diesel fuel in a 9 to 1 ratio (90\% diesel fuel, 10\% dual-purpose water), the final water-in-diesel emulsion would consist of $90 \%$ diesel fuel, $6 \%$ pure water, $3 \%$ methanol, and $1 \%$ surfactant.

\section{Proof-of-Concept Prototype Assembly}

Fig. 2 shows a prototype of the emulsification chamber for the on-board ultrasonic WiDE fuel system. Using the prototype, preliminary testing was conducted to evaluate real-time emulsion fuel production and combustion emissions. The in-line, three-way cross configuration provided an effective and compact method to emulsify water and fuel on demand. The prototype emulsification chamber was constructed by modifying a stainless steel straight fitting coupler with an inner diameter of $1.27 \mathrm{~cm}(0.5$ inches). Two holes were drilled on either side of the coupler; 2 copper tubes, each with inner diameters of $0.3175 \mathrm{~cm}$ (0.125 inches), were welded into these holes: one for the fuel inlet and the other for the water inlet. A third copper tube with an inner diameter of $0.3175 \mathrm{~cm}$ (0.125 inches) was welded onto one end of the coupler to provide an emulsion fuel outlet. An ultrasonic processor, with an outer diameter of $1.27 \mathrm{~cm}$ (0.5 inches), was inserted onto the other end of the coupler through a compression-fitting nut. The ultrasonic processor's probe intruded into the center of the emulsification chamber and had direct contact with the liquid. During experimentation, fuel and water were continuously fed by pump into the emulsification chamber and the ultrasonic processor homogenized (emulsified) the liquids as they emerged from the emulsification chamber.

\section{Diesel and Biodiesel Fuel Preparation}

Conventional diesel and biodiesel were the control fuels in this study. The base diesel fuel was commercial petroleum diesel from a diesel pump at a local gasoline station. The biodiesel fuel used was produced from the transesterification of vegetable oil with methanol $\left(\mathrm{CH}_{3} \mathrm{OH}\right)$ catalyzed by sodium hydroxide lye $(\mathrm{NaOH})$.

Vegetable oil-based biodiesel was prepared by the author using the following steps. Under mechanical agitation, 1,500 $\mathrm{mL}$ of raw canola oil was heated

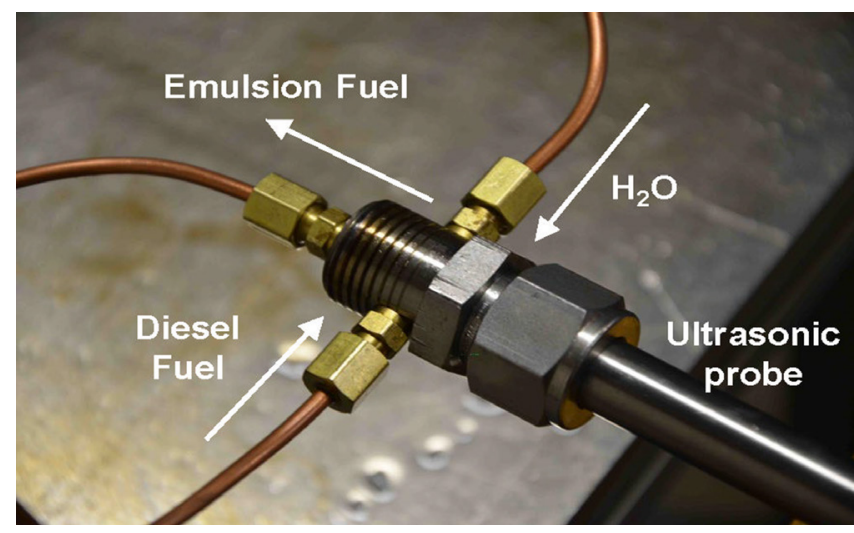

FIGURE 2. Proof-of-concept prototype of in-line, flow-through, water-in-diesel emulsification chamber. Constructed with a 0.5 -inch straight fitting coupler. Note the 2 inlets, 1 outlet, and the ultrasonic processor port.

to $480{ }^{\circ} \mathrm{K}$ in a glass conical flask to boil out water contamination (i.e., moisture in the oil). The oil in the flask was then allowed to cool to room temperature (approximately $293^{\circ} \mathrm{K}$ ). Separately, 10 grams of sodium hydroxide was dissolved into $300 \mathrm{~mL}$ of methanol at $350^{\circ} \mathrm{K}$. Once the canola oil, in the flask, had cooled to room temperature, the freshly prepared sodium hydroxide/methanol solution was added into the flask. To allow for chemical reaction, the mixture was stirred vigorously-using a $750 \mathrm{~W}$ ultrasonic processor (Sonics \& Materials $^{\circledR}$ VCX 750) - for 10 minutes at $320^{\circ} \mathrm{K}$, until the canola oil and methanol/lye solution had been thoroughly mixed. The mixture was then allowed to settle, undisturbed, for 96 hours. After settling, 2 distinct liquid layers were formed: a top layer of dark yellow crude ester and a bottom layer of viscous, dark orangered glycerol. The top layer, approximately $1,300 \mathrm{~mL}$ of crude biodiesel, was carefully separated from the bottom glycerol layer and placed into another flask. This crude biodiesel was then washed using deionized water to remove residual methanol, lye, glycerin, and impurities. In the biodiesel washing process, a handheld sprayer was used to gently spray $650 \mathrm{~mL}$ of slightly warmed $\left(300{ }^{\circ} \mathrm{K}\right)$ deionized water into the crude biodiesel. The water-biodiesel mixture was then left undisturbed for 24 hours, allowing the water to naturally separate out of the biodiesel and settle at the bottom of the flask. Because the contaminants in the biodiesel (i.e., residual methanol, lye, glycerin, impurities) had a much stronger affinity for water compared to biodiesel oil, the water carried the contaminants down to the bottom of the flask. This milky, contaminated, water at the bottom of the flask was carefully siphoned out, yielding 1,225 $\mathrm{mL}$ of pure biodiesel. This pure biodiesel was 
translucent and golden-yellow, which is characteristic of cleansed and uncontaminated biodiesel. The $\mathrm{pH}$ of the biodiesel was 7.0, indicating the successful removal of impurities; the presence of methanol or lye would have resulted in an acidic solution.

\section{Ultrasonic Cavitation-Induced Emulsion}

High-intensity ultrasound methods have long been used for the mixing, emulsifying, and dispersing of liquids. Mechanically sonicating liquids at high intensities generates intense sonic pressure waves that propagate throughout the liquid media, causing the rapid formation and growth of micron-sized vacuum bubbles or "voids." When the bubbles attain their resonant size, they vibrate violently and collapse; a phenomenon termed cavitation.

The implosion of the cavitation bubbles in the liquid can release highly localized energy: local heating of up to $5,000{ }^{\circ} \mathrm{K}$, pressures above $10^{3} \mathrm{~atm}$, heating and cooling rates above $10^{10} \mathrm{~K} / \mathrm{s}$, and liquid jet streams (Suslick 1990; Thompson and Doraiswamy 1999). These conditions result in effective mixing that can thoroughly homogenize immiscible component liquids, creating a sole emulsified liquid (Fig. 3).

The revolutionary feature of the WiDE fuel system was the use of this ultrasound-induced cavitation technique to continuously emulsify fuel and water to make water-in-diesel emulsion fuel on-board a running diesel vehicle.

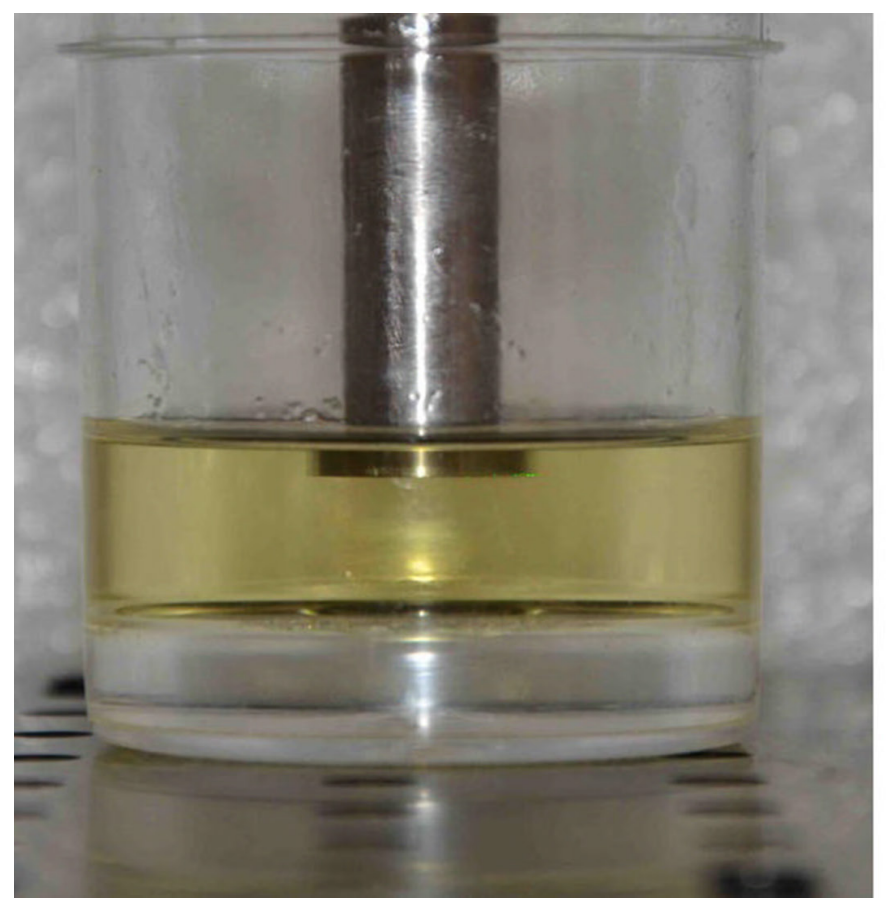

\section{Ultrasonic Processor: Amplitude to Watts Calibration}

An ultrasonic processor from Sonics \& Materials $^{\circledR}$ (Model No. VCX 750) was used for the prototype system. The processor had a variable power output between $10 \mathrm{~W}$ and $750 \mathrm{~W}$ with a frequency of 20 $\mathrm{kHz}$. The processor had a $136 \mathrm{~mm}$ ultrasonic probe made of titanium alloy (Ti-6Al-4V) and a probe tip with a diameter of $13 \mathrm{~mm}$ ( 0.5 inches). The probe's processing capability was $50 \mathrm{~mL}$ to $250 \mathrm{~mL}$. Although the amplitude of the ultrasonic processor could be set to any desired level between $10 \%$ and $80 \%$, the actual power applied to liquids could not be predetermined. In fact, the operational power delivered into the sample depended on the resistance to movement (i.e., high-frequency vibrations of the probe tip in relation to the viscosity of the liquid substance). To calibrate the given processor system, the probe tip resistance was estimated for diesel fuel and water by measuring the output power of the preselected amplitudes from $10 \%$ to $80 \%$ in increments of $10 \%$. This test resulted in a linear relationship between the amplitude applied to the processor and the output power of the ultrasonic processor, which is represented by the following empirical equation:

$$
\text { Output Power (W) = Amplitude (\%) - } 10
$$

(EQUATION 1)

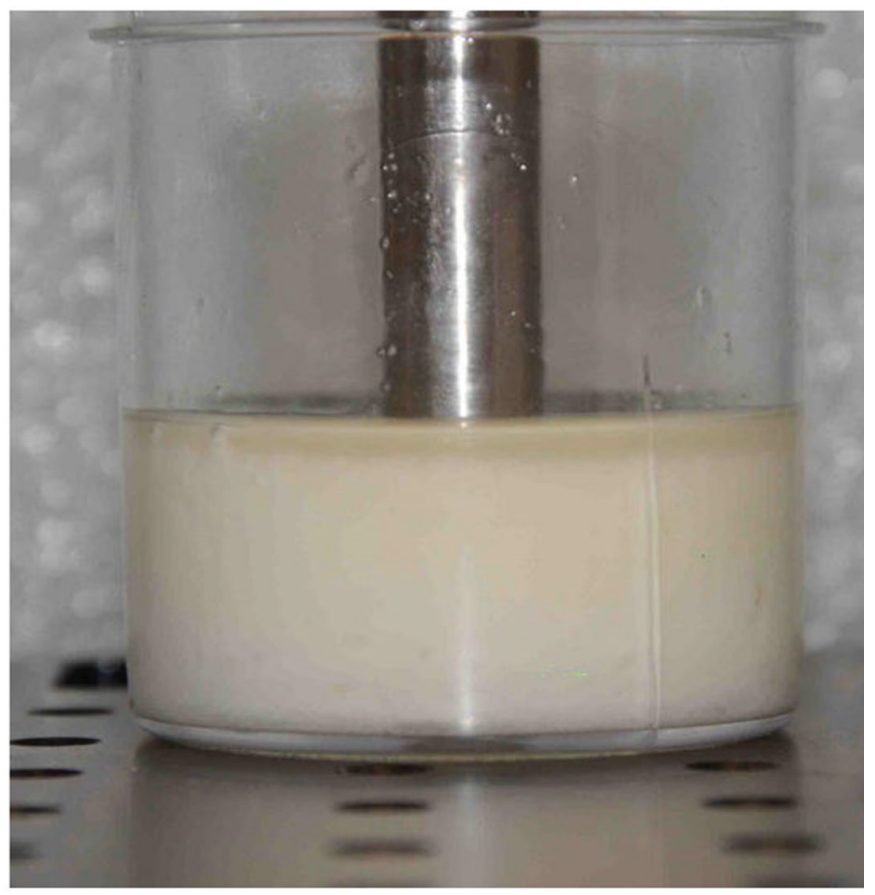

FIGURE 3. Separated diesel and water with ultrasonic processor inserted (left). Water-in-diesel fuel emulsion (right). Fuel and water were emulsified with less than 1.0-second exposure to ultrasound-induced cavitation. 


\section{Ultrasonic Processor: Energy Measurement for Complete Emulsion}

Knowledge of the energy required for complete emulsification of diesel fuel and water is crucial for automobile electrical management. For this purpose, the total ultrasonic energy applied to emulsify 1 part $(5 \mathrm{~mL})$ of distilled water and 9 parts $(45$ $\mathrm{mL}$ ) of diesel was measured. This calibration test showed that a minimum energy of 68 joules was required for complete emulsification. Since the total mixture volume was $50 \mathrm{~mL}$, the energy usage was calculated to be 1.4 joules $/ \mathrm{mL}$. By multiplying the energy usage times the fuel flow rate of $1 \mathrm{~mL} / \mathrm{sec}$ of the present experiment, the minimum ultrasonic power required to operate the proposed in-line WiDE system was estimated to be $1.4 \mathrm{~W}$. While fuel flow rates in actual diesel engines-found in transportation vehicles, for example-would be at least 10 times more than the fuel flow rate used in the present study, the total energy estimated to keep the processor running within a fuel control circuit would not be a burden to a typical diesel engine's electrical system.

\section{Combustion and Fuel Spray Experimentation}

Fluid reaction experiments using an open-flame apparatus were conducted to assess the validity of the WiDE concept. Four types of fuel were used for comparison: $100 \%$ conventional petroleum diesel (D100), 100\% pure biodiesel (B100), water-in-diesel emulsion fuel, and water-in-biodiesel emulsion fuel. For the emulsion fuels, the percentage of the dualpurpose water mixture in the total fuel volume was either $2 \%$ or $3 \%$. The dual-purpose water mixture consisted of $63 \%$ water, 30\% methyl alcohol, and $7 \%$ surfactant. It should be noted that the combustion burner showed apparent flame instability, with intermittent flameout, for emulsion fuels with water content greater than 3\%. It is reasonable to speculate that this instability can be improved by configuring the burner to utilize a more advanced fuel injection technique and/or a more sophisticated flame holding mechanism. However, such arrangements were beyond the scope of the current research.

The combustion testing apparatus was set up in an industrial facility in Warrensville Heights, Ohio, as seen in Fig. 4.

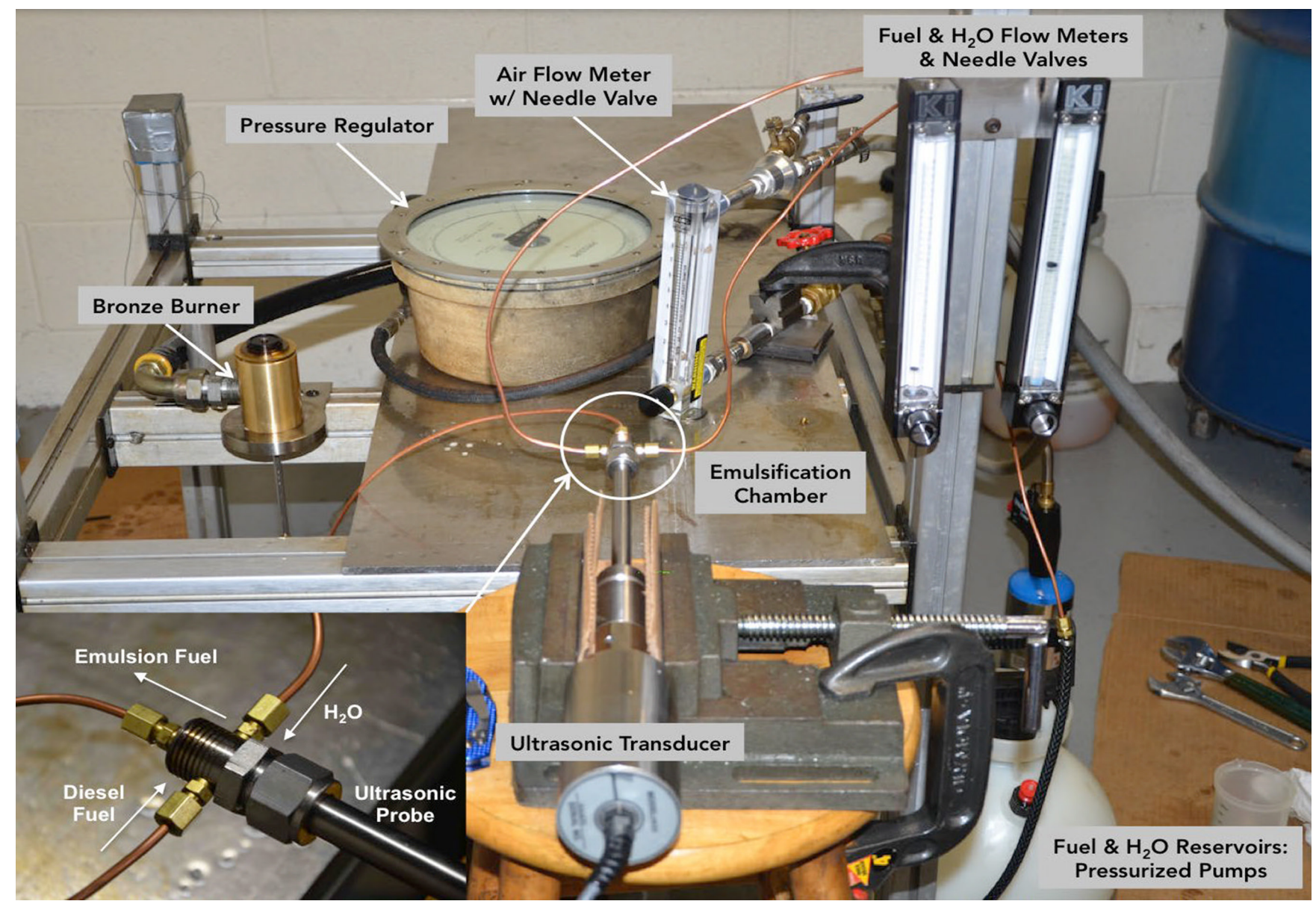

FIGURE 4. Experimental combustion apparatus with prototype emulsification chamber (inset) 
A schematic of the testing apparatus is shown in Fig. 5. A pair of garden sprayers were used as pressurized fuel and water reservoirs, both pumped to a source pressure of $3 \mathrm{~atm}(303,975 \mathrm{~Pa})$. This pressure was found to be sufficient to provide constant airflow through the piping and burner system for the period of combustion testing. Direct-read rotameters (flow meters) with needle valves were used to control the oxidizer airflow, the fuel flow, and the water flow. The fuel flow rate was $\approx 1.90$ liter/ hour and the water flow rate was $\approx 0.057$ liter/hour. The oxidizer airflow rate was maintained at 28.3 liter/ minute throughout all the experiments.

A laboratory-scale burner manufactured by Sun Valley Technology Inc., Warrensville Heights, Ohio, was used for the combustion flame and fuel spray experiments. The burner employed radial-entry, counter-swirl airflow to atomize or "break up" the liquid fuel stream into a fine spray and sustain a subsequent combustion reaction. The air-assisted (or so-called "air-blast") nozzle of the fuel injector generates a hollow cone spray pattern as described in a latter section. The nozzle-end opening was $5.5 \mathrm{~mm}$ in diameter, and the fuel orifice was $0.5 \mathrm{~mm}$ in diameter. In this unique injection system the fuel spray angle and droplet characteristics were, in general, functions of the airflow rate. The ultrasonic processor, when in operation, mixed the fuel and water as they flowed through the emulsification chamber: the residence time of the fluids in the chamber was less than 2 seconds. The water-in-fuel emulsion was then fed into the burner, which produced a stable, upward directed, fuel spray. The emulsion fuel spray (above the burner) was ignited, generating a luminous flame. This open flame provided excellent opportunity for non-intrusive optical diagnostics. The fuel emulsification system was deactivated for the experiments using pure diesel or biodiesel fuels.

Direct imaging for both combustion flame and non-reacting fuel spray was carried out using a digital SLR camera (Nikon ${ }^{\circledR}$ D7000; 16.2 MP, 18 to 105 $\mathrm{mm}$ lens). The camera was secured on a tripod and set in-line with the burner's center axis. Over 50 photographic images of the combustion flame and the fuel spray were taken for each fuel variety. For the purpose of investigating fuel spray patterns, a compact and economical laser imaging technique was developed. This fuel-spray visualizer was an opto-mechanical system consisting of a green laser pointer (Nd: $\mathrm{YVO}_{4}$ diode-pumped solid-state laser, 5 $\mathrm{mW}$ power, $532 \mathrm{~nm}$ wavelength, $5 \mathrm{~mm}$ in diameter) and a pair of mirrors (Fig. 6). One of the 2 mirrors, located along the laser beam path, was attached to a gear motor. The laser beam emitted from the laser pointer was reflected upward by the first mirror and subsequently reflected horizontally by the second mirror. During operation, the second mirror was spun continuously by the motor and thus vertically scanned the laser beam in a circular motion, forming a

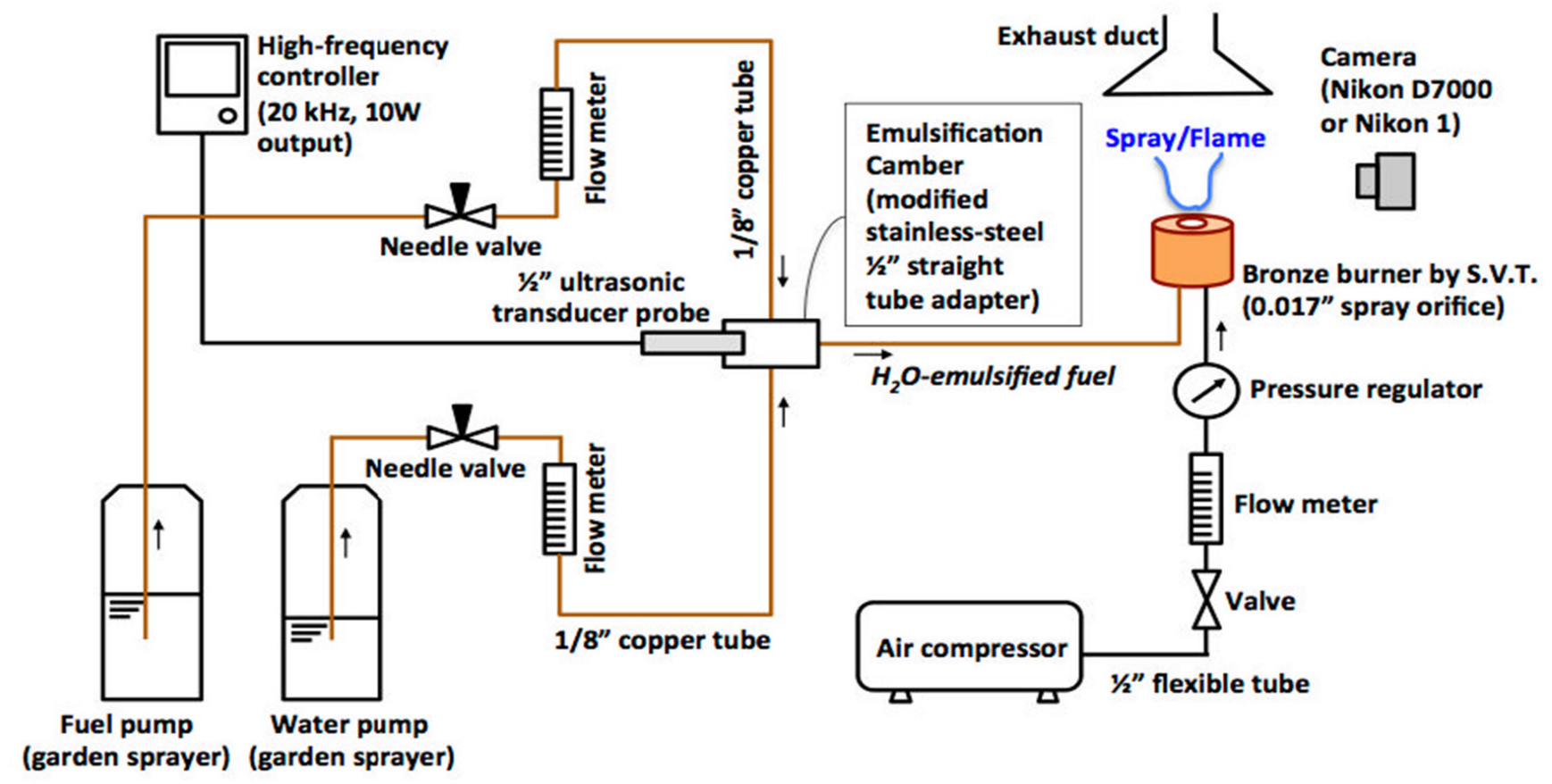

FIGURE 5. Schematic of the experimental setup of the proof-of-concept WiDE fuel supply system for combustion experiments and diagnostic imaging 


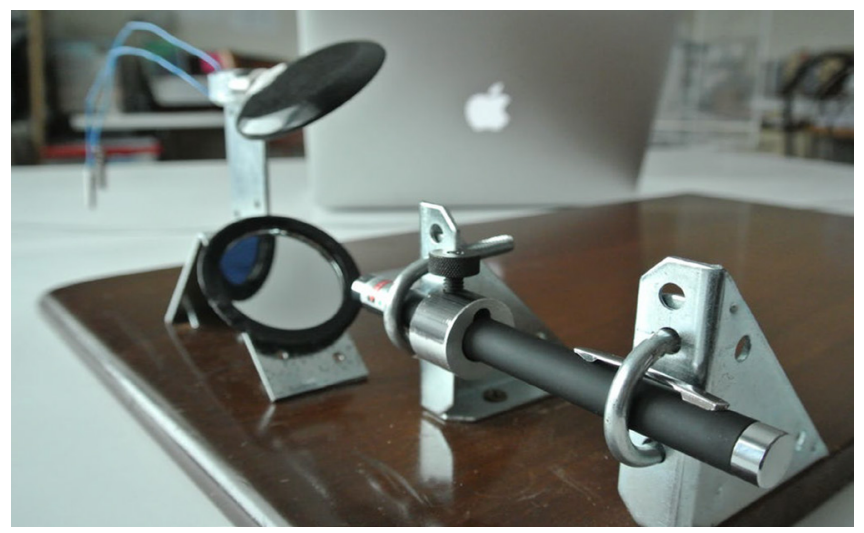

FIGURE 6. Laser-scanning fuel-spray visualizer with motored rotating mirror used for spray-pattern measurements

"laser sheet" with approximately $1 \mathrm{~mm}$ thickness. The exposure time was optimized such that the laser beam scanned once across the fuel nozzle plane at the given spinning speed. This laser beam scattered off the fuel droplets and effectively visualized the spray formation, becoming a "highlighter" of the spray pattern. The camera was positioned at an angle perpendicular to the laser beam axis, to obtain vivid laser scattering images.

\section{RESULTS AND DISCUSSION Data Analysis I: Flame Color Intensity}

The PM emissions of the water-emulsion fuels were evaluated and compared with traditional fuels. Data were acquired using a visible-wavelength flame imaging technique and processed using a novel computer program written in MATLAB ${ }^{\circledR}$. Representative flame images of pure biodiesel fuel and water-in-biodiesel fuels $(1 \% \mathrm{~W}$ and $2 \% \mathrm{~W})$ are shown in Fig. 7a. PM emissions, predominately soot, are carbon micro-particles with typical formation between $\mathrm{C}_{1}$ and $\mathrm{C}_{3}$. When the PM particles are heated by combustion, they radiate as blackbody, producing a yellow-orange luminous flame. No other species is expected to produce such strong radiation over the range of visible wavelengths; therefor, measuring the total light intensity of the yellow luminescence in flames is considered an effective and convenient method to quantitatively estimate the PM emission volume fraction.

In contrast, a dark-blue to emerald-green flame color arises predominantly from chemiluminescence due to the intermediate species in the reaction process. Hydrocarbon-fueled combustion, including diesel combustion, emits blue-colored chemiluminescence primarily originating from the following: (1) excitedstate hydroxyl radicals, $\mathrm{OH}^{*}$, in the ultraviolet region (thus no contribution to the present visible-wavelength analysis); (2) excited-state methylidyne radicals, $\mathrm{CH}^{*}$, in the 420 to $440 \mathrm{~nm}$ wavelength band; and (3) excited-state diatomic carbon, $\mathrm{C}_{2}{ }^{*}$, in the 460 to 470 $\mathrm{nm}$ and 500 to $520 \mathrm{~nm}$ wavelength bands (Nau et. al 2012). Here, an asterisk $\left({ }^{*}\right)$ denotes molecular species in electronically excited states. These intermediate species are only formed in an ongoing chemical reaction with substantial heat release. Therefore, the chemiluminescence in flames, in principle, indicates the region where active combustion reaction is taking place. Such blue flames generally suggest a lower level of PM presence, signifying near complete combustion. Consequently, the blue flame intensity can be used as a basis of dynamic combustion rate. The photographs recorded in the experiment showed that the yellow flames were usually formed above the blue flame regions, indicating that PM is a by-product of combustion chemistry.

Based on the above, a computer image-processing algorithm was developed in MATLAB $^{\circledR}$. This algorithm applied a color-segmentation technique to the flame images to separate or "crop out" the yellow-colored pixels-those with soot-induced luminosity - from the background (Fig. 7b). Using the same process, the blue-colored pixels - those with the flame chemiluminescence - were also isolated from the background. Unlike an image acquisition technique using optical bandpass filters, the present flame-color analysis is a data post-processing technique. There is an error factor associated with this post-processing technique; a small number of pixels in each image were near the threshold value in the hue color scale, making it difficult to differentiate the individual intensity of the blue and yellow flames. Therefor, some blue-flame images still contained yellow-colored pixels. Read-out counts from these boundary pixels with mixed colors contributed to an uncertainty of roughly $5 \%$ in the PM emission level estimation described below. In spite of this unavoidable ambiguity in the present imageprocessing, the practical and economical convenience of the proposed software technique was favored over hardware-based acquisition techniques (which tend to be significantly more expensive and require multiple cameras and optical components).

The specific hue-color ranges - those that identified the soot luminosity and blue chemiluminescencewere pre-determined based on the statistical value of the color histograms obtained from the original images (Fig. 7b). In the present study, the hue angles between $80^{\circ}$ and $270^{\circ}$ were used to identify yellow 


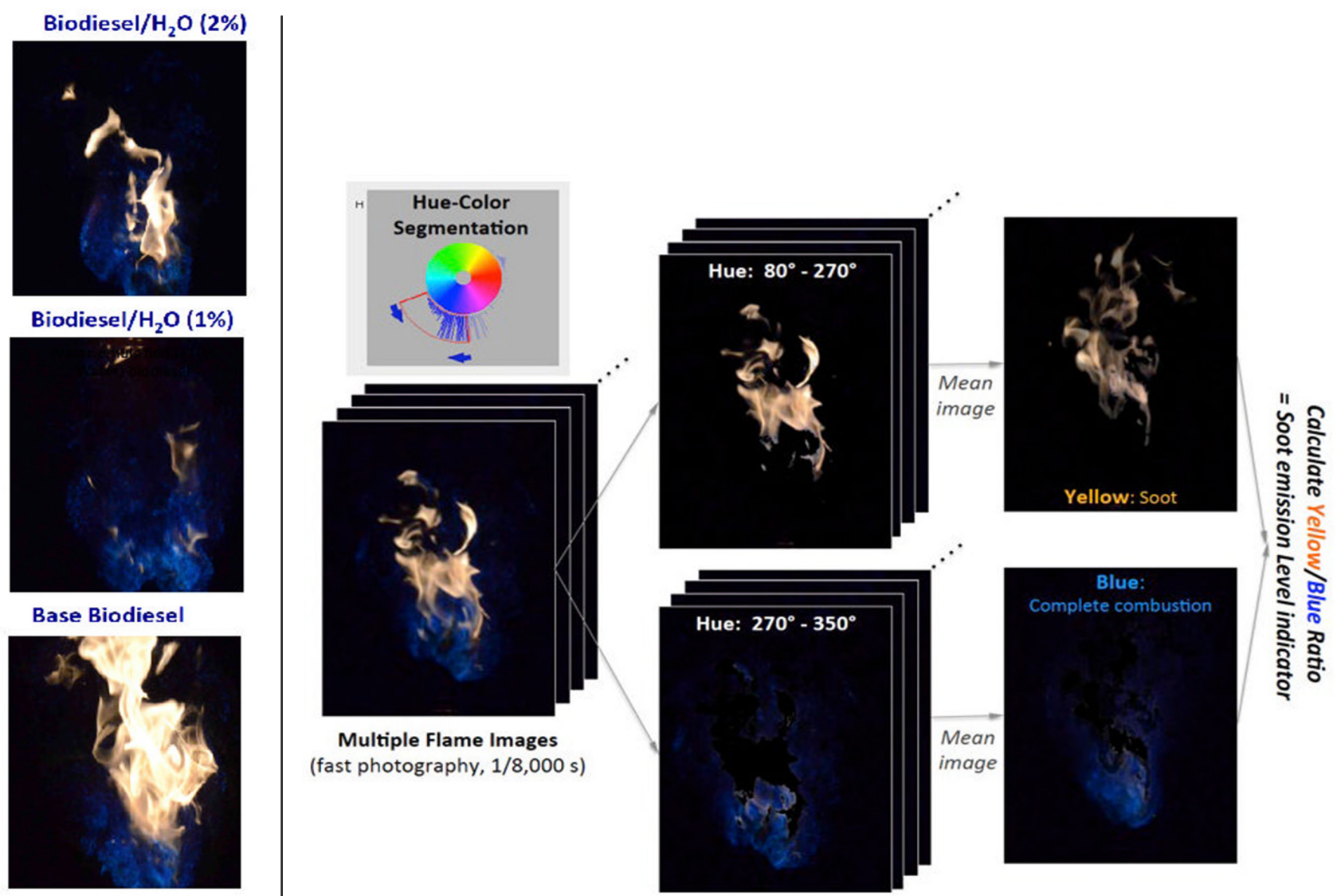

(a)

(b)

FIGURE 7. Image post-processing approach to estimate PM emissions from combustion flame color. (a) Examples of visible flame images from combustion of base biodiesel and water-in-biodiesel emulsion fuels with $1 \%$ and $2 \%$ water content. (b) Hue-color segmentation to isolate blue images from yellow images for classification analysis.

pixels, and the hue angles between $270^{\circ}$ and $350^{\circ}$ represented the blue pixels. For the data analysis, the flame images (more than 50 images in total) were averaged for each color classification. The summation of the yellow pixel-intensity was then computed and normalized by the blue pixel-intensity sum. This value, hereafter called yellow/blue ratio, or Y-B ratio, served as an optical quantity of PM volume fraction (i.e., an indicator of particulate matter emission level).

The mean pixel (matrix element) value of the averaged flame image was computed by Equation 2, where $I$ is the pixel intensity of each matrix element ( $\mathrm{x}$, $y), X=3264$ and $Y=4928$ are the numbers of pixels on CCD sensor coordinate, and $i$ is the color type (either yellow or blue) of the image. Finally, the ratio of the mean pixel values of the yellow and blue luminosity (i.e., Y-B ratio $(R y / b))$ was computed by Equation 3, where an increase in $R y / b$ indicates the higher PM volume fraction, and a decrease in $R y / b$ indicates the lower PM volume fraction. Note that $R y / b$ is a normalized value and thus is designed to cancel out the differences in the overall pixel intensities among the fuel varieties.

\section{Data Analysis II: Fuel Spray Pattern}

Diesel engine performance depends on many different factors; one of them is fuel spray pattern characteristics. Although the present combustion testing was limited to experiments on an open-air burner, and testing conditions did not necessarily match conventional diesel engine specifications, the experimental data on fuel spray patterns proved to be useful in gaining insight into the fundamental issues of WiDE fuel combustion. Fuel spray quality can be defined as the degree of atomization and uniformity of droplet size distribution. The spatial and temporal structure of the fuel injection play critical roles in

$$
\begin{aligned}
& \overline{I_{i}}=\sum_{1,1}^{X, Y} I_{(x, y)} / X \cdot Y \\
& R_{y / b}=\overline{I_{\text {yellow }}} / \overline{I_{\text {blue }}}
\end{aligned}
$$


fuel vaporization, fuel-air mixing, and subsequent combustion-all of which dictate fuel efficiency and emissions in the diesel engine.

The fuel injection system used in the present burner relied upon the shear flow generated by the counter-swirling oxidizer air to achieve fine fuel spray, which is usually a preferred arrangement for combustion engines. In order to dissect such a spray formation, it was necessary to use a temporally and spatially resolved imaging technique such as the aforementioned laser-scanning diagnostic technique. Fig. 8 shows two-dimensional laser-sheet scattering images of fuel droplets/clusters. The images in Fig. $8 \mathrm{a}$ are 2 representative images out of more than 50 fuel spray images obtained. Pixel intensity histograms for biodiesel and water-in-biodiesel emulsion are also shown on the right side of Fig. 8. Two images with similar histograms were chosen in order to conduct a non-biased, comparative analysis. The 2 images have similar spray formation; both sprays slightly lean toward the left side of the burner center axis due to the characteristic swirling motion of the burner used.

The 2 types of fuel produced a common spraypattern profile: a full cone. Notice that the sprays are not hollow cones. Strong, saturated scattering near the spray nozzle and a cone angle of approximately $90^{\circ}$ are evident. To reveal distinct behaviors of the spray formation of the 4 fuel variations, the laser scattering images were post-processed via 2 image filtering techniques that are available in Microsoft ${ }^{\circledR}$
PowerPoint ${ }^{\circledR} 2011$ (Version 14.2.1) as artistic filtering features: the "Cutout" intensity-threshold filter and the "GlowEdges" intensity-gradient filter.

The "Cutout" intensity-threshold filter generated 6 individual layers from the original spray image, sorted in increasing order of pixel intensities as shown in Fig. $8 \mathrm{~b}$. The level of image pixel intensity represents the level of spray advancement over the spreading angle of the spray (No. 1 being the most intense and No. 6 being the least intense scattering). Each layer was superimposed to the next layer. Observation of these intensity-filtered image layers was used to study the trajectories and the transition of the spray formation over the area imaged. In accordance with the Mie scattering theory, the initial fuel spray near the orifice of the burner had a higher scattering intensity due to dense fuel spray and larger droplets near the orifice (Le Gal et al. 1999). In contrast, as the droplets traveled farther away from the nozzle, the fuel stream broke up into smaller clusters and created a fine mist around the spray boundary. Because the smaller droplets did not scatter the laser light as much as the larger droplets, the scattering intensity decreased.

Fig. 9 shows the 2 "GlowEdges"-filtered images of base biodiesel and water-emulsified biodiesel. These images were processed to enhance features by detecting the edges where the pixel intensity gradients were higher than the preset threshold. This filter technique was especially useful to visualize individual droplets or clusters along the outer spray boundaries.

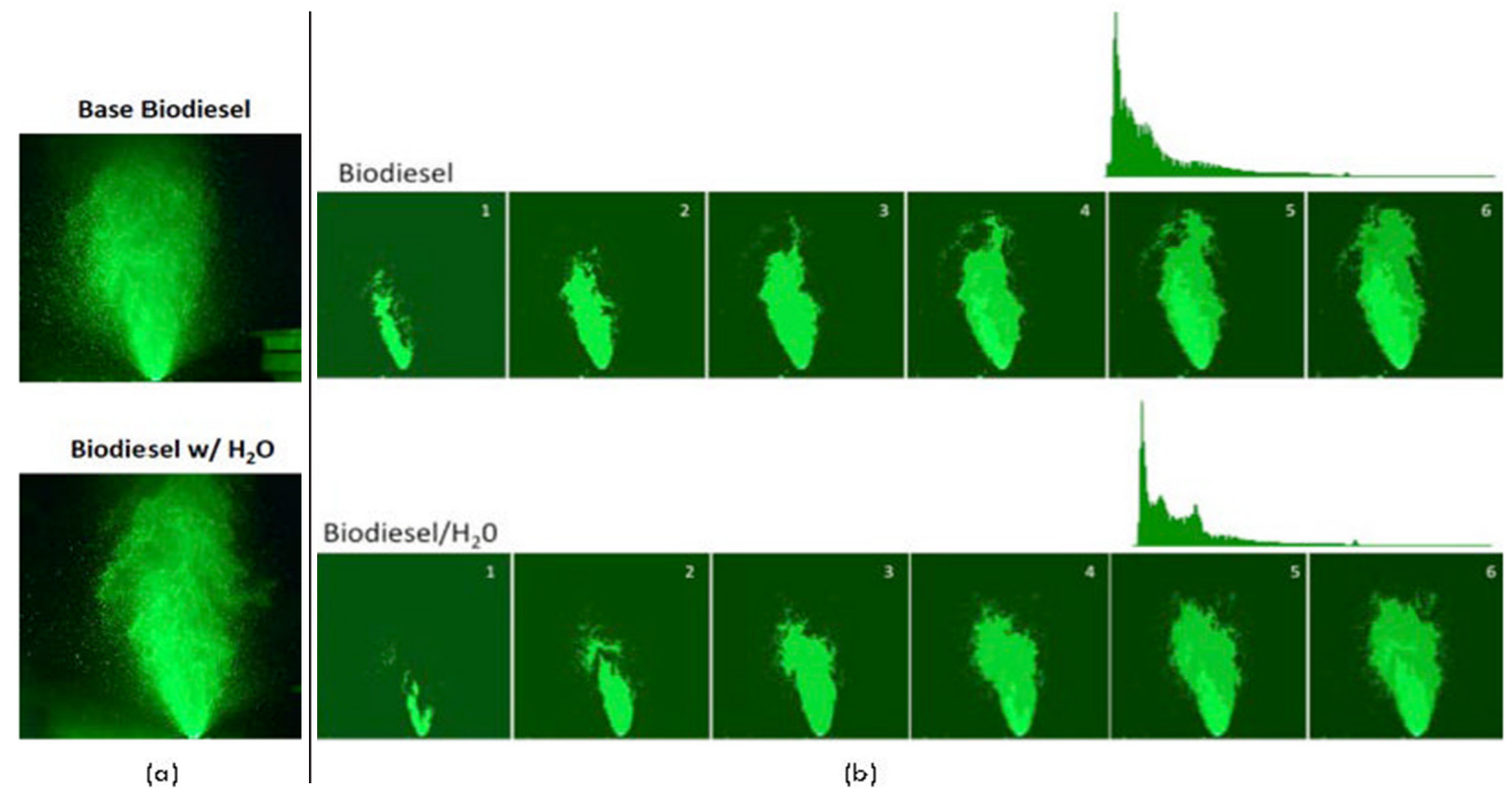

FIGURE 8. (a) Laser-visualized fuel spray images of non-reacting base biodiesel and water-in-biodiesel fuel. (b) Intensity-threshold filtered images, indicating "time-evolution" of spray formation. Inset histograms show the intensity distribution of the images. 
The technique was also instrumental in determining the injection cone angles. By enhancing these spray features, the characteristic atomization of the fuel variations was magnified for detailed observation. It was found that water-in-biodiesel fuel-when compared to conventional biodiesel fuel-has a smaller spray injection cone angle, and more uniform and finely atomized formation. The biodiesel fuel seems to suffer from unevenness in spray formation with some larger droplet clusters. It is also noticeable that the base biodiesel shows large gaps with no droplets between the wakes of airflow, which can lead to combustion instability. It is speculated that lower viscosity, due to the water contents in fuel and positive changes in surface tension, helped the water-in-biodiesel fuel to exhibit a more evenly distributed spray formation with smaller droplets.

\section{PM Emission Level Estimation: Yellow-Blue (Y-B) Ratio}

Fig. 10 shows the results of a Y-B ratio $(R y / b)$ analysis on several combinations of fuel emulsions, plus the control diesel and biodiesel fuels. Each data set was normalized by the maximum value of the control in order to compare the results across the different camera shutter speeds. It should be noted that the absolute value of $R y / b$ (before normalization) changed with the shutter speed. The data taken with the longer exposure time showed higher $R y / b$. This increase in Y-B ratio calculation can be explained by the fact that PM radiation is much stronger in intensity than chemiluminescence. PM radiation is therefore more dominant, and optically overwhelms chemiluminescence, as the camera's exposure time increases.

Fig. 10a shows a promising trend of the on-board ultrasonic WiDE fuel supply system approach, indicating PM emissions from biodiesel combustion

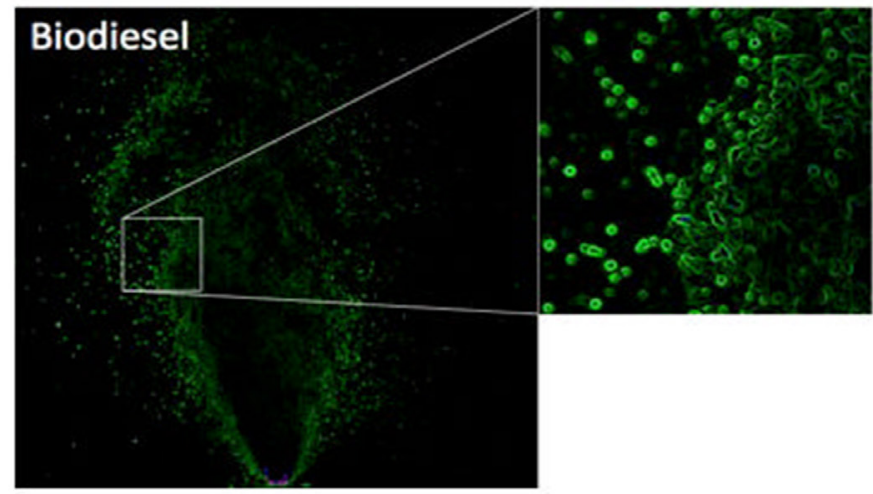

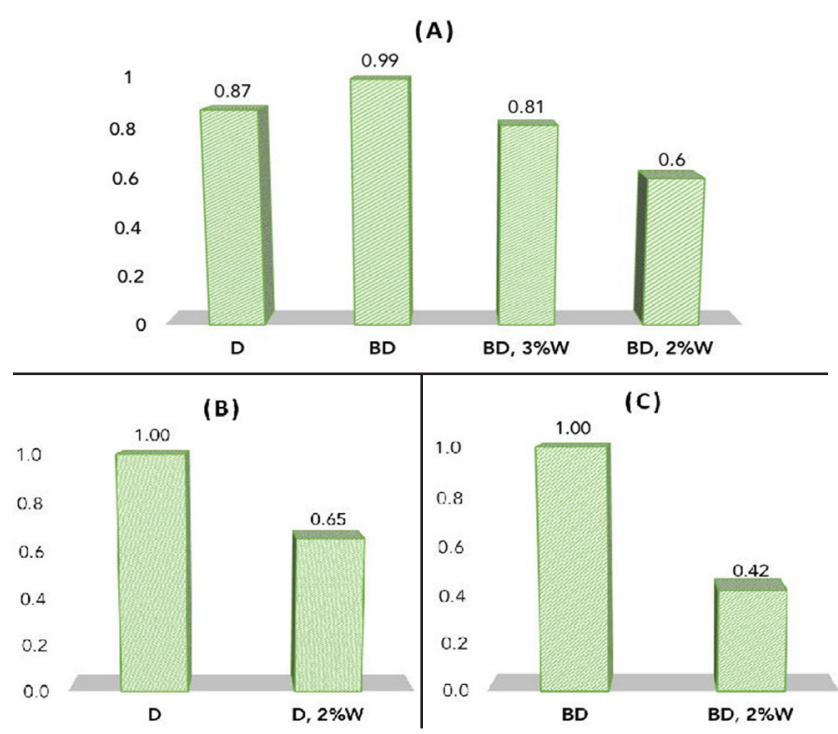

FIGURE 10. Comparison of PM (soot) emissions based on normalized Y-B ratio (vertical axis) of various fuel types. D: base diesel; BD: base biodiesel; W: water volume percentage (water-in-fuel emulsion). Imaging exposure (shutter speed): (A) 1/8,000; (B) 1/800; (C) 1/200.

can be reduced by $19 \%$ and $40 \%$ via $3 \%$ and $2 \%$ water-emulsification, respectively. This observation also corresponds with another biodiesel test result shown in Fig. 10c, which suggests an even greater PM emission reduction of $58 \%$ by introducing water-emulsion $(2 \% \mathrm{~W})$. Fig. $10 \mathrm{~b}$ indicates the PM emissions from WiDE fuel are 35\% lower than the PM emissions from conventional diesel fuel. With an increase of water content in the emulsion the PM emissions are expected to be lowered even further. It is important to note in Fig. 10a that biodiesel combustion generally produces higher amounts of PM than petroleum diesel combustion unless wateremulsion is used. This is a unique finding because the present data suggests that water-emulsion is a necessary treatment for biodiesel fuel to become truly environmentally friendly in applications to diesel engines.

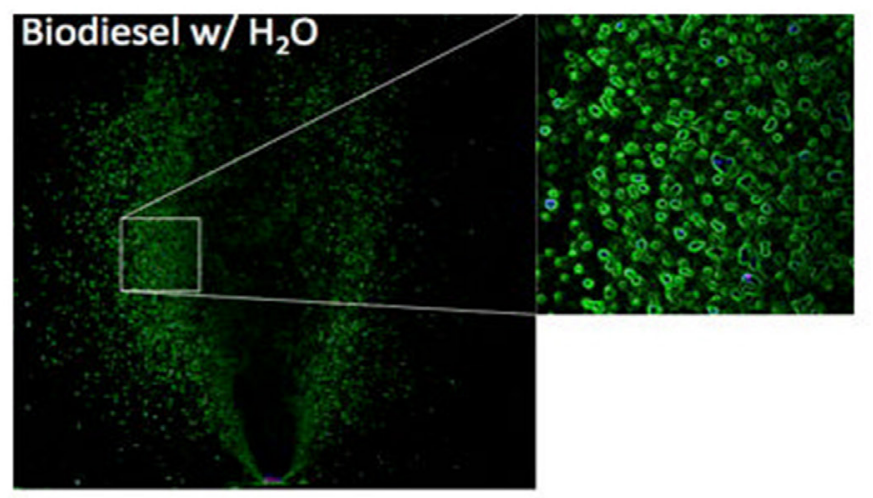

FIGURE 9. Fuel spray laser scattering images, post-processed by an intensity-gradient filtering method 
This PM emission reduction is primarily a result of the micro-explosion phenomenon in WiDE fuel combustion. In WiDE fuel, microscopic water droplets are dispersed in the continuous diesel fuel phase. During combustion the emulsion droplets are heated by convective and radiative heat transfer from surrounding combustion gas and flame; subsequently, the enclosed water droplets become superheated. This superheated state is thermodynamically metastable; a condition maintained as long as no phase transformation occurs within the droplet. As the droplet temperature approaches the superheat limit, the occurrence of bubble nucleation dominatesleading to the internal formation of vapor bubbles, rapid evaporation, and consequently the disintegration of the superheated liquid.

When a water/fuel emulsion is heated, the water droplets vaporize first because water is more volatile. This vaporization causes an explosion of the whole droplet, violently disintegrating the droplet into fine particles (<20 microns). Consequently, more surface area of the fine droplets is exposed to the air, enhancing the fuel/air mixing process. As a result, the combustion reaction and the burning efficiency are improved, thus suppressing the formation of PM and unburned hydrocarbons. Additionally, $\mathrm{NO}_{X}$ emissions from WiDE fuel are lowered due to the reduced adiabatic temperature of the flame; there must be heat loss associated with the evaporation of the microscopic water droplets within the fuel.

\section{CONCLUSIONS AND OUTLOOK}

Emulsion fuel is emerging as a prime alternative fuel for both transport and stationary diesel engines. The growing interest in this type of fuel is driven by its benefits: simultaneous reduction of both nitrogen oxides and particulate matter, while minimizing the impact to combustion efficiency. Despite its attractiveness, WiDE fuel has not been widely used due to critical deficiencies.

This paper describes the development of a technology to overcome the obstacles impeding the commercialization of water-in-diesel emulsion fuel. The on-board ultrasonic water-in-diesel emulsion (WiDE) fuel system utilizes ultrasonic cavitation to produce the water emulsion in situ, before the fuel injector. Because this concept uses an onboard in-line approach, it essentially eliminates the concerns of emulsion instability. This technology is economically advantageous as it eliminates costly emulsion manufacturing plants, expenses for special transportation, and infrastructure of dedicated fuel dispensers.

The low-emission capability of this technology has been confirmed through open-air combustion experiments - including quantitative tests using novel (but readily available) optical diagnostics and imageprocessing techniques. Through this proof-of-concept study, the system was proven to function as designed. It was capable of producing quality emulsion fuel using ultrasonic cavitation in a real-time, flow-through fashion, and was able to subsequently supply stable WiDE fuel for combustion. This prototype shows strong potential for the continued development of a robust, energy efficient, and reliable on-board ultrasonic WiDE fuel supply system. If brought to fruition, it will enable the commercialization of WiDE fuel as an alternative source of energy for future diesel engines as well as current engines through a retrofit approach.

In the future, in-depth studies on pollutant formation (PM, $\mathrm{NO}_{X}, \mathrm{SO}_{X}, \mathrm{CO}, \mathrm{HC}$, black smoke, etc.) in commercial diesel engines need to be conducted: specifically testing the WiDE blend with various surfactants. Based on the results of such research, a simplified but effective numerical and experimental combustion model should be developed. This model would optimize the water content in the emulsion for best engine performance and emission in each engine operating condition (idle, low/high load). Endurance and durability testing of both the fast-switching three-way solenoid valve and the low-power high-frequency ultrasonic processor are necessary before further prototyping the WiDE fuel system for engine implementation. In practical aspects, waterproof common rail electronics must be developed in order to make the WiDE fuel system more applicable to modern diesel engine design. Finally, the emulsification (mixing) chamber design must be successfully scaled-up to accommodate the fuel-flow rates found in heavy-vehicle- and industrialdiesel engines.

\section{ACKNOWLEDGEMENTS}

The authors would like to thank Dr. Frank Sun of Sun Valley Technology Inc. for his assistance in combustion testing at his facility in Warrensville Heights, Ohio. The authors also acknowledge Ms. Linda Rader of The Ohio State University for her editorial assistance. 


\section{LITERATURE CITED}

Alahmer A, Yamin J, Sakhrieh A, Hamdan MA. 2010. Engine performance using emulsified diesel fuel. Energy Convers Manag. 51(8):1708-1713. https://doi.org/10.1016/j. enconman.2009.11.044

Alander TJA, Leskinen AP, Raunemaa TM, Rantanen L. 2004. Characterization of diesel particles: effects of fuel reformulation, exhaust aftertreatment, and engine operation on particle carbon composition and volatility. Environ Sci Technol. 38(9):27072714. https://doi.org/10.1021/es030129j

Armas O, Ballesteros R, Martos FJ, Agudelo JR. 2005. Characterization of light duty diesel engine pollutant emissions using water-emulsified fuel. Fuel. 84(7-8):1011-1018. https:// doi.org/10.1016/j.fuel.2004.11.015

Bagley ST, Gratz LD, Johnson JH, McDonald JF. 1998. Effects of an oxidation catalytic converter and a biodiesel fuel on the chemical, mutagenic, and particle size characteristics of emissions from a diesel engine. Environ Sci Technol. 32(9): 1183-1191. https://doi.org/10.1021/es970224q

Basha JS, Anand RB. 2011. An experimental study in a CI engine using nanoadditive blended water-diesel emulsion fuel. Int J Green Energy. 8(3):332-348. https://doi.org/10.1080/1543 5075.2011 .557844

Binks BP. 1998. Modern aspects of emulsion science. Cambridge: Royal Society of Chemistry. 430 p.

Farfaletti A, Astorga C, Martini G, Manfredi U, Mueller A, Rey M, De Santi G, Krasenbrink A, Larsen BR. 2005. Effect of water/fuel emulsions and a cerium-based combustion improver additive on HD and LD diesel exhaust emissions. Environ Sci Technol. 39(17):6792-6799. https://doi.org/10.1021/ es048345v

Ghojel J, Honnery D, Al-Khaleefi K. 2006. Performance, emissions and heat release characteristics of direct injection diesel engine operating on diesel oil emulsion. Appl Therm Eng. 26(17-18):2132-2141. https://doi.org/10.1016/j. applthermaleng.2006.04.014

Gill LJ, Blakeman PG, Twigg MV, Walker AP. 2004. The use of $\mathrm{NO}_{X}$ adsorber catalysts on diesel engines. Top Catal. 28(1-4):157-164. https://doi.org/10.1023/B:TOCA.0000024345.85369.73

Guan B, Zhan R, Lin H, Huang Z. 2014. Review of state of the art technologies of selective catalytic reduction of $\mathrm{NO}_{X}$ from diesel engine exhaust. Appl Therm Eng. 66(1-2):395-414. https://doi.org/10.1016/j.applthermaleng.2014.02.021

Ithnin AM, Ahmad MA, Bakar MA, Rajoo S, Yahya WJ. 2015. Combustion performance and emission analysis of diesel engine fuelled with water-in-diesel emulsion fuel made from low-grade diesel fuel. Energy Convers Manag. 90:375-382. https://doi.org/10.1016/j.enconman.2014.11.025

Ithnin AM, Noge H, Kadir HA, Jazair W. 2014. An overview of utilizing water-in-diesel emulsion fuel in diesel engine and its potential research study. J Energy Inst. 87(4):273-288. https:// doi.org/10.1016/j.joei.2014.04.002

Kadota T, Yamasaki H. 2002. Recent advances in the combustion of water fuel emulsion. Prog Energy Combust Sci. 28(5):385404. https://doi.org/10.1016/S0360-1285(02)00005-9

Kagawa J. 2002. Health effects of diesel exhaust emissions-a mixture of air pollutants of worldwide concern. Toxicology. 181-182:349-353. https://doi.org/10.1016/S0300483X(02)00461-4

Kean AJ, Sawyer RF, Harley RA. 2000. A fuel-based assessment of off-road diesel engine emissions. J Air Waste Manag Assoc. 50(11):1929-1939. https://doi.org/10.1080/10473289.2000 .10464233

Kerminen VM, Makela TE, Ojanen CH, Hillamo RE, Vilhunen JK, Rantanen L, Havers N, von Bohlen A, Klockow D. 1997. Characterization of the particulate phase in the exhaust from a diesel car. Environ Sci Technol. 31(7):1883-1889. https:// doi.org/10.1021/es960520n

Koebel M, Elsener M, Marti T. 1996. $\mathrm{NO}_{X}$-reduction in diesel exhaust gas with urea and selective catalytic reduction.
Combust Sci Technol. 121(1-6):85-102. https://doi. org/10.1080/00102209608935588

Le Gal P, Farrugia N, Greenhalgh DA. 1999. Laser sheet dropsizing of dense sprays. Opt Laser Technol. 31(1):75-83. https://doi. org/10.1016/S0030-3992(99)00024-9

Lewtas J.2007. Air pollution combustion emissions: characterization of causative agents and mechanisms associated with cancer, reproductive, and cardiovascular effects. Mutat Res. 636(13):95-133. https://doi.org/10.1016/j.mrrev.2007.08.003

Lif A, Holmberg K. 2006. Water-in-diesel emulsions and related systems. Adv Colloid Interface Sci. 123-126:231-239. https:// doi.org/10.1016/j.cis.2006.05.004

Lin CY, Wang KH. 2003. The fuel properties of threephase emulsions as an alternative fuel for diesel engines. Fuel. 82(11):1367-1375. https://doi.org/10.1016/S00162361(03)00021-8

Lloyd AC, Cackette TA. 2001. Diesel engines: environmental impact and control. J Air Waste Manag Assoc. 51(6):809-847. https://doi.org/10.1080/10473289.2001.10464315

Maiboom A, Tauzia X. 2011. $\mathrm{NO}_{X}$ and PM emissions reduction on an automotive HSDI diesel engine with water-in-diesel emulsion and EGR: an experimental study. Fuel. 90(11):31793192. https://doi.org/10.1016/j.fuel.2011.06.014

Nadeem M, Rangkuti C, Anuar K, Haq MR, Tan IB, Shah SS. 2006. Diesel engine performance and emission evaluation using emulsified fuels stabilized by conventional and gemini surfactants. Fuel. 85(14-15):2111-2119. https://doi. org/10.1016/j.fuel.2006.03.013

Nau P, Krüger J, Lackner A, Letzgus M, Brockhinke A. 2012. On the quantification of $\mathrm{OH}^{*}, \mathrm{CH}^{*}$, and $\mathrm{C}_{2}{ }^{*}$ chemiluminescence in flames. Appl Phys B. 107(3):551-559. https://doi.org/ $10.1007 / \mathrm{s} 00340-012-5006-9$

Neuberger M, Schimek MG, Horak Jr F, Moshammer H, Kundi M, Frischer T, Gomiscek B, Puxbaum H, Hauck H. 2004. Acute effects of particulate matter on respiratory diseases, symptoms and functions: epidemiological results of the Austrian Project on Health Effects of Particulate Matter (AUPHEP). Atmos Environ. 38(24):3971-3981. https://doi.org/10.1016/j. atmosenv.2003.12.044

Ochoterena R, Lif A, Nydén M, Andersson S, Denbratt I. 2010. Optical studies of spray development and combustion of water-in-diesel emulsion and microemulsion fuels. Fuel. 89(1):122-132. https://doi.org/10.1016/j.fuel.2009.06.039

Pope III CA, Dockery DW. 2006. Health effects of fine particulate air pollution: lines that connect. J Air Waste Manag Assoc. 56(6):709-742. https://doi.org/10.1080/10473289.2006.1 0464485

Prasad R, Bella VR. 2010. A review on diesel soot emission, its effect and control. Bull Chem Reac Eng Catal. 5(2):69-86. https://doi.org/10.9767/bcrec.5.2.794.69-86

Reşitoğlu İA, Altinişik K, Keskin A. 2015. The pollutant emissions from diesel-engine vehicles and exhaust aftertreatment systems. Clean Technol Environ. 17(1):15-27.https://doi.org/10.1007/ s10098-014-0793-9

Stein HJ. 1996. Diesel oxidation catalysts for commercial vehicle engines: strategies on their application for controlling particulate emissions. Appl Catal B. 10(1-3):69-82. https:// doi.org/10.1016/0926-3373(96)00024-0

Suslick KS. 1990. Sonochemistry. Science. 247(4949):1439-1445. https://doi.org/10.1126/science.247.4949.1439

Sydbom A, Blomberg A, Parnia S, Stenfors N, Sandström T, Dahlen SE. 2001. Health effects of diesel exhaust emissions. Eur Respir J. 17(4):733-746. https://doi.org/10.1183/0903 1936.01.17407330

Thompson LH, Doraiswamy LK. 1999. Sonochemistry: science and engineering. Ind Eng Chem Res. 38(4): 1215 - 1249. https://doi.org/10.1021/ie9804172

Van Setten BA, Makkee M, Moulijn JA. 2001. Science and technology of catalytic diesel particulate filters. Catal Rev. 43(4):489-564. https://doi.org/10.1081/CR-120001810 